\title{
HAEMANGIO-ENDOTHELIOMA OF THE SPLEEN AND LIVER
}

\author{
BY \\ R. G. TASKER \\ From the Department of Pathology, Ormskirk County Hospital, Ormskirk
}

(RECEIVED FOR PUBLICATION SEPTEMBER 5, 1957)

With the exception of the reticuloses, primary malignant tumours arising in the spleen are rare, but from time to time examples have been reported which appear to be angioblastic in character and in some cases seem to cause metastases in the liver and elsewhere (Langhans, 1879 ; Theile, 1904 ; Jores, 1908 ; Dowd, 1915 ; Wright, 1928; Schlopsnies, 1929; Paine, 1931; De Navasquez, 1936; Wright, 1949 ; Abrahams and Hughes, 1952).

Although most authorities are agreed that malignant angioblastic tumours do occasionally occur, there is considerable doubt as to whether the tumours which appear to have arisen in the spleen are examples of true angioblastic malignant tumours or whether they represent multifocal systemic lesions (Willis, 1948). The case to be described appears to fall into this group and is reported because of its unusual interest, especially in regard to the age of the patient, and in the hope that eventually a true evaluation of these tumours may be forthcoming.

\section{Case Report}

The patient was an obese woman of 82 years who for some time previously had been suffering from degenerative cardiac disease with hypertension. For 18 months she had complained of constant left abdominal pain. A large mass was found in the left hypochondrium. At first this was thought to be a renal tumour but was later considered to be an enlarged spleen. A mild orthochromic anaemia was present. She remained in reasonably good health although showing progressive weakness and dyspnoea on exertion. She was finally sent to hospital in congestive heart failure, with ascites and dilated abdominal veins. She died shortly after admission.

\section{Necropsy Report}

The body was that of an obese woman showing cyanosis of the lips and extremities.

The brain and spinal cord showed no gross changes. There was a mild atheromatous degeneration of the cerebral vessels.

The heart was enlarged with marked hypertrophy of the left ventricle. The myocardium contained a patchy fibrosis. The valves were normal. The coronary arteries were narrowed by an extensive atheroma.

The lungs were congested and oedematous. NoA structural changes were apparent. The pleural cavi $-\stackrel{0}{0}$ ties contained a small quantity of fluid.

A moderate amount of free fluid was present in the peritoneal cavity. The spleen was enlarged, measur 3 ing $18 \mathrm{~cm} . \times 23 \mathrm{~cm} . \times 13 \mathrm{~cm}$. and weighing $490 \mathrm{~g}$. I was oval and the surface smooth. The capsule was closely bound to the left cupola of the diaphragm $\vec{\bullet}$ The cut surface was mottled with areas of spongy/ vascular tissue interspersed with hard white trabecu: lated tissue. There were a few small scattered cysto filled with blood. Anatomically the splenic ands hepatic vessels were normal, but the splenic arteryo was enlarged and the vein dilated.

The liver showed a fine cirrhosis. Large numbersD of vascular tumours were scattered throughout the left lobe, but there were no tumours in the right lobe. $\overrightarrow{0}$ Those on the surface did not protrude above it. The tumours varied in size from 2 to $3 \mathrm{~mm}$. up to $3 \mathrm{~cm}$

The other abdominal organs appeared normal and no enlarged lymph nodes were to be found. Nक्. abnormality was found in the marrow and no bone? deposits were detected.

\section{Histology}

Spleen.-The splenic tissue is almost entirely re placed by angiomatous tissue and hyalinized fibrouso tissue. Only a few degenerate Malpighian corpuscles are to be found, and these appear to be largely reo placed by angioblastic tissue which is capillary insome areas whereas in others a cavernous structure is present. The vessels continuously branch and anastomose and form a tangled mass, but in places there is no canalization and this gives an appearances of new vessels being formed. There is, however, n⿳ sign of active growth. In other areas the tumour is more cellular and sheets of endothelial cells are pres sent without any apparent vascular formation (Fig. 1) Here the cell outlines are indistinct, but the size appears to be regular and, apart from the nuclei being large and hyperchromic, there are few of thक्ष accepted criteria of malignancy and mitoses are ver® rare. The capsule of the spleen is normal in appear 8 ance and shows no sign of invasion.

Liver.-Sections of the nodules in the liver show similar pattern to that seen in the vascular areas 


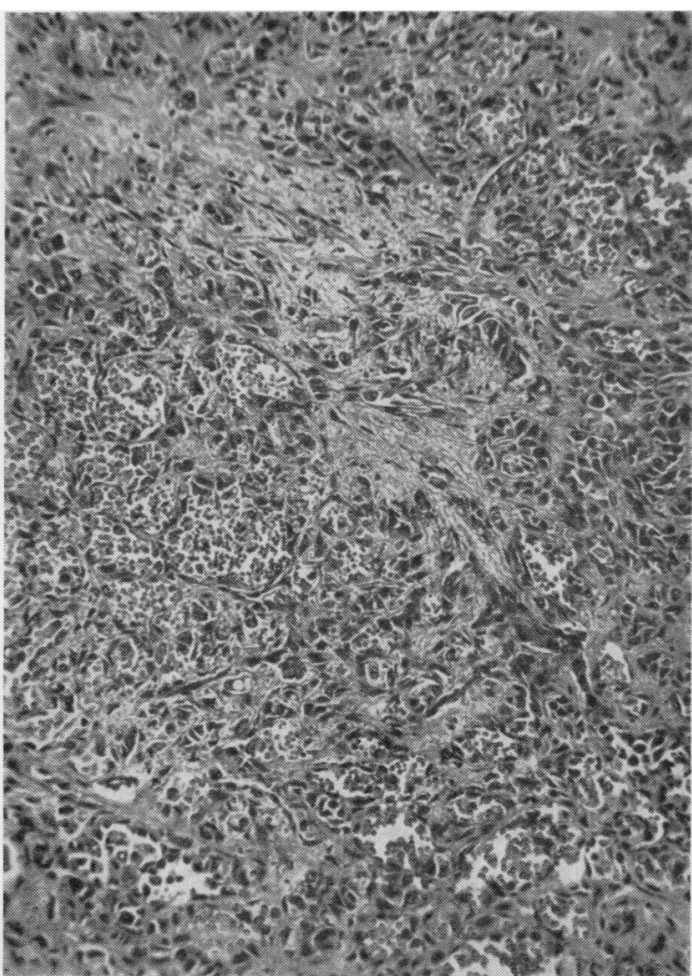

FIG. 1.-Section of spleen showing sheets of endothelial cells and open vascular channels. $(\times 95$.

the spleen, although there is more variation in the size and shape of the cells. Once again mitoses are almost completely absent although the endothelial cells give the appearance of infiltrating between the liver cells (Fig. 2). Careful examination, however, reveals that these cells merge into the normal capillary pattern of the lobule and do not seem to be spreading up the capillary channels nor do they show active growth, and indeed in many parts there are wellformed capillaries (Fig. 3). The liver cells are being destroyed by pressure.

\section{Discussion}

Although proliferative angiomatous lesions are extremely common, there is doubt as to whether they should be considered as true tumours or congenital vascular malformations. Harvey, Dawson, and Innes (1940) have stated that the term " angioma" should include all pathological vascular proliferations which are not regenerative, inflammatory, or mechanical disturbances of the normal circulatory arrangements and that there is little point in stressing the difference between congenital malformations and true tumour. It is admittedly sometimes extremely difficult, if not at present impossible, to differentiate between some malformations and tumour. Nevertheless the attempt is worth while, for it is by striving to solve such problems that advances are made in understanding tumour genesis.

If true angioblastic tumours do occur it seems reasonable to assume that a more malignant form might exist than the simple, ubiquitous angioma, but a review of the literature reveals that such aggressive lesions are extremely rare, and Willis (1948 and 1952) is reluctant to admit the existence of malignant angioblastic neoplasms, preferring to consider them as merely vasoformative variants of mesenchymomas, and maintaining that the majority of reported cases are examples of multifocal systemic lesions. Winston Evans (1956) seems to agree with this view but at the same time has illustrated the author's case as an example of the so-called malignant haemangioendothelioma.

The case reported here, which appears to resemble in many respects that described by De Navasquez (1936), contains many features which at first sight seem to indicate malignant propensities. The formation of anastomosing, imperfect

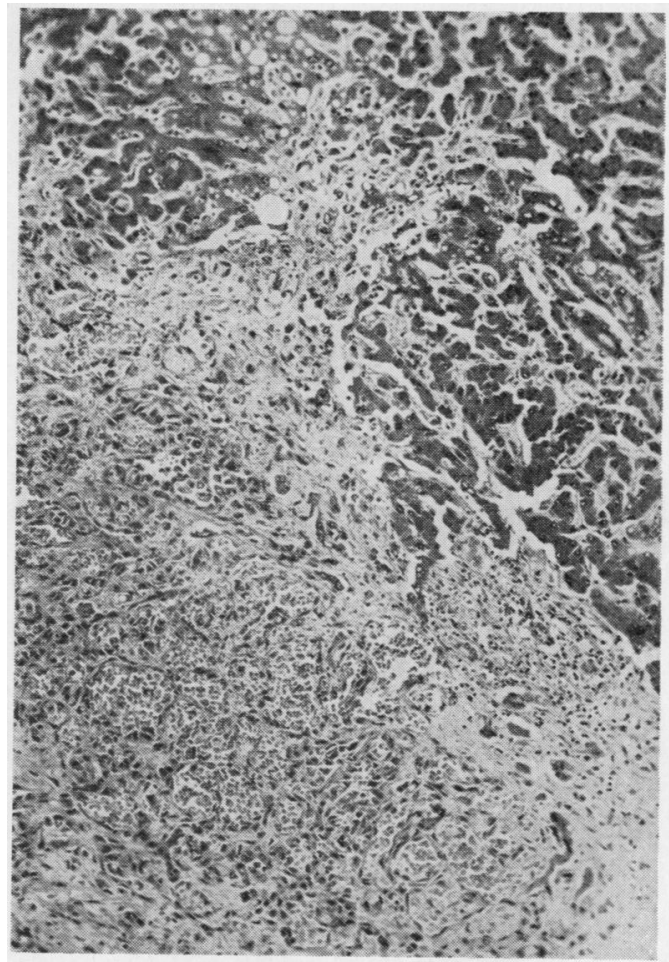

FIG. 2.-Section of liver, showing well-formed vascular channels in the tumour. At the edge the endothelial cells show apparent invasion with some destruction of the liver cells. ( $\times 95$.) 


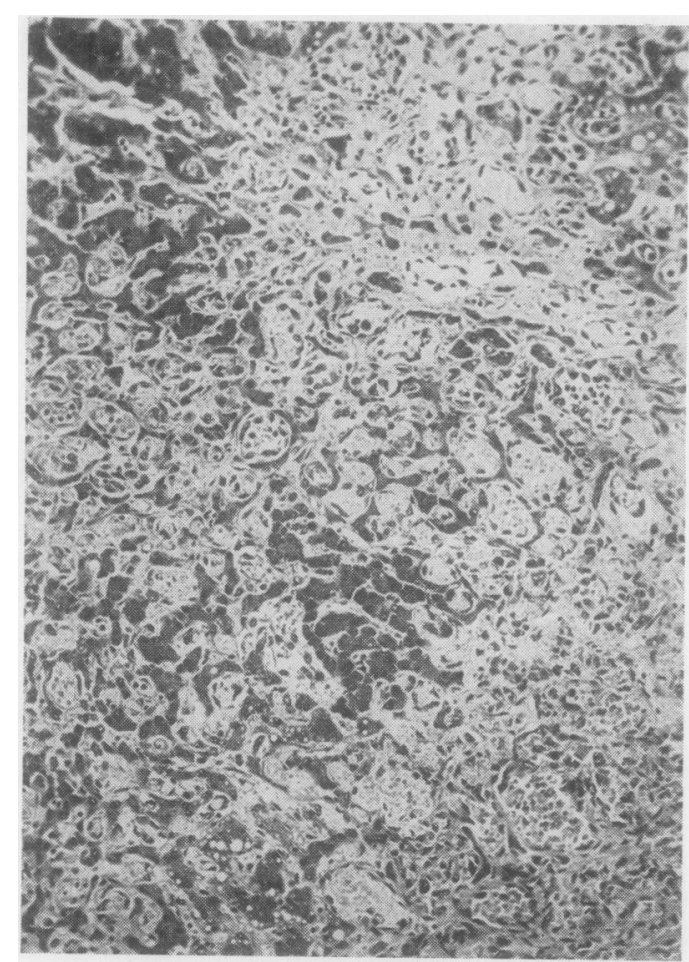

FIG. 3.-Section of liver showing open vascular channels destroying the liver cells by pressure. $(\times 95$.

blood channels by rounded endothelial cells with hyperchromic nuclei, and the filling of the vascular lumen with heaped-up cells, agree closely with the criteria of malignancy in these tumours as laid down by Stout (1943). It is also tempting to assume that the nodules in the liver, showing an apparent infiltration, are secondary metastatic growths from the primary growth in the spleen.

There are, however, many features which argue against a malignant interpretation. In spite of these histological characters, the cytology in the splenic tumour shows no evidence of rapid, high proliferative potentiality, and for two years the size of the spleen appeared to be constant. It might be that progressive fibrosis counteracted the proliferation of the cells causing their regression and conversion to fibrous tissue, a well-recognized feature of angiomata. The cells of the lesion also exhibit few or no mitoses and no evidence of active capillary sprouting as described by Stout (1943). In addition there is no suggestion of invasion of the splenic capsule in spite of the fact that the whole of the spleen appears to be converted into vascular tissue. If the tumour had been found to be confined to the spleen then there would be no reason to consider it to be malignant, although a type of tumour is recognized in which $\stackrel{\vec{F}}{\vec{F}}$ the primary growth is well differentiated but a? recurrence is subsequently found to be truly malignant in character and disposition (Hill and Stout, $\frac{\bar{c}}{\bar{c}}$ 1942).

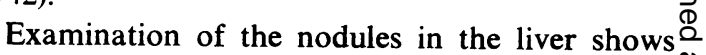
that here again there is no evidence of active growth ; nevertheless there is an apparent invasion $\vec{\circ}$ of the liver with destruction of the cells. Careful scrutiny, however, reveals that this apparent in- $\vec{\omega}$ vasion is only occurring in one or two areas $\frac{\Omega}{2}$ around the nodules. The endothelial cells in these? parts are well differentiated and indeed in some $\overrightarrow{-}$ cases show perfect capillary formation. It wouldi seem that these areas are the "feeding" vessels $\vec{f}$ of the angioma, and the destruction of the liver cells is due to compression owing to a recent 5 opening up of more channels. Willis (1948) has $\vec{z}$ pointed out how poorly demarcated are hamartomas and how their mingling with normal $\stackrel{\widehat{\supset}}{\supset}$ tissues gives a false appearance of infiltrative $\vec{\oplus}$ activity. It is difficult to conceive that a tissue, of so capable of rapid proliferation as is vascular endothelium, should show so little sign of proliferative growth.

Another feature of considerable interest is the occurrence of cirrhosis. This feature was also $\stackrel{0}{\varnothing}$ present in the case described by Ogilvie and $\stackrel{\square}{\circ}$ Mackenzie (1936). They believed that their $\overrightarrow{\overrightarrow{0}}$ tumour arose in a previously cirrhotic liver. The 3 association of cirrhosis with hepatic endothelial tumour has been regarded as evidence favouring the theory of their origin by a process of regeneration of endothelial channels (Evans, 1956). If this:were so it would seem possible that the same 3 . process could occur in a fibrotic spleen. The vascular structure of the spleen and the left lobe $\frac{\circ}{3}$ of the liver are closely bound together and it might be expected that any stimulus affecting the one would also affect the other. It is noteworthy that in spite of the large size of the splenic growth and multiple hepatic angiomatous nodules there $N$ was no evidence of angiomatous tumours in the $N$ lungs or elsewhere nor could there be found any $N$ evidence of haemopoiesis as described by Paine (1931) and Hastings-James (1949).

It is easier to conceive of a vascular defect giving rise to an angiomatous malformation of the spleen $\stackrel{\mathbb{Q}}{\rightarrow}$ and, to a lesser extent, the left lobe of the liver than tumours of the kind described metastasizing. Such a defect might remain indolent, growing $\overrightarrow{\mathbb{D}}$ slowly throughout life until because of the onset $\frac{O}{\mathbb{Q}}$ of a congestive heart failure the enlarged spleen $\varrho$ was noticed during an examination. This congestive failure, together with a slowly advancing 
cirrhosis of the liver and fibrosis of the spleen, might be the cause of the opening of the vascular channels with compression of the liver cells, so deforming them as to give an appearance suggestive of malignant invasion.

Such an explanation, denying the malignancy of this tumour, is more in keeping with present ideas of the mutability of cells. If the endothelial cells should undergo neoplastic change they are more likely to give rise to a mesenchymoma or possibly a fibrosarcoma, perhaps with vasoformative tendencies, and not to reasonably well-formed angiomatous tissue.

\section{Summary}

A case of haemangio-endothelioma involving the spleen and liver is described and illustrated.
Reasons are given for believing that this is a systemic malformation rather than a true tumour.

\section{REFERENCES}

Abrahams, A. M., and Hughes, J. Howell (1952). Brit. J. Surg., 40, 68. De Navasquez, S. (1936). J. Path. Bact., 42, 65i.

Dowd, C. N. (1915). Ann. Surg., 62, 177.

Evans, R. W. (1956). Histological Appearances of Tumours, p. 62.

Harvey, W. F.. Dawson, E. K., and Innes, J. R. M. (1940). E.lin. med. J., 47, 513

Hastings-James, R. (1949). J. Path. Bact., 61, 49

Hill, R. P., and Stout, A.P. (1942). Arch. Surg. (Chicago), 44, 723.

Jores, L. (1908). Zbl. allg. Path. path. Anat., 19, 662.

Langhans, T. (1879). Virchows Arch. path. Anat., 75, 273.

Ogilvie, R. F., and Mackenzie, I. (1936). J. Pl.h. B I:I., 43, 143 and 429.

Paine, C. G. (1931). Ibid., 34, 139.

Schlops ies, W. (1929). Virchows Arch. path. Anat., 27 \, 85.

Stout, A. P. (1943). Ann. Surg., 118, 445.

Theile (1904). Virchows Arch. path. Anat., 178, 296

Willis, R. A. (1948). Pathology of Tumours, p. 702. Butterworth,

London. The Spread of Tumours in the Human Body, 2nd ed., p. 109. Butterworth, London.

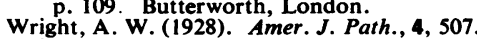

Wright, M. (1949). Arch. Path. (Chicago), 47, 180. 